\title{
The Influence of NiTi Alloy on the Cyclic Fatigue Resistance of Endodontic Files
}

\author{
Celia Ruiz-Sánchez ${ }^{1}$, Vicente Faus-Llácer ${ }^{1}$, Ignacio Faus-Matoses ${ }^{1}$, \\ Álvaro Zubizarreta-Macho ${ }^{2, *} \mathbb{E}$, Salvatore Sauro ${ }^{3,4}$ and Vicente Faus-Matoses ${ }^{1}[\mathbb{C}$ \\ 1 Department of Stomatology, Faculty of Medicine and Dentistry, University of Valencia, 46010 Valencia, Spain; \\ celia.ruiz@uv.es (C.R.-S.); fausvj@uv.es (V.F.-L.); ignacio.faus@uv.es (I.F.-M.); vicente.faus@uv.es (V.F.-M.) \\ 2 Department of Endodontics, Faculty of Health Sciences, Alfonso X El Sabio University, 28691 Madrid, Spain \\ 3 Department of Dentistry, Faculty of Health Sciences, CEU Cardenal Herrera University, 46115 Valencia, \\ Spain; salvatore.sauro@uchceu.es \\ 4 Department of Therapeutic Dentistry, I.M. Sechenov First Moscow State Medical University, \\ 119146 Moscow, Russia \\ * Correspondence: azubimac@hotmail.com
}

Received: 30 October 2020; Accepted: 20 November 2020; Published: 21 November 2020

\begin{abstract}
Background: The aim of this study was to analyze the influence of NiTi alloy in endodontic rotary instruments on cyclic fatigue resistance. Methods: One hundred and sixty-four (164) sterile endodontic rotary files were selected and distributed into the following study groups: A: 25.08 F2 ProTaper Universal (PTU) $(n=41)$; B: 25.06 X2 ProTaper Next (PTN) $(n=41)$; C: 25.08 F2 ProTaper Gold (PTG) $(n=41)$, and D: 25.06 ProFile Vortex Blue (PVB) $(n=41)$. A cyclic fatigue device was designed to conduct the static cyclic fatigue tests with stainless steel artificial root canals systems with $250 \mu \mathrm{m}$ apical diameter, $60^{\circ}$ curvature angle, $5 \mathrm{~mm}$ radius of curvature, $20 \mathrm{~mm}$ length, and $6 \%$ (25.06) and $8 \%$ taper (25.08). Failure of the endodontic rotary instrument was detected by a single operator through direct observation and was also filmed to allow measurement of the exact time to failure. Results were analyzed using the ANOVA test and Weibull statistical analysis. Results: All pairwise comparisons presented statistically significant differences between the time to failure for the NiTi alloy study groups $(p<0.001)$, except between the PTN and PVB study groups $(p=0.379)$. In addition, statistically significant differences between the number of cycles to failure for the NiTi alloy study groups $(p<0.001)$ were also observed. Conclusions: The NiTi CM-Gold wire alloy of the ProTaper Gold endodontic rotary files resulted in greater resistance to cyclic fatigue than ProFile Vortex Blue, ProTaper Next, and ProTaper Universal endodontic rotary files.
\end{abstract}

Keywords: endodontics; cyclic fatigue; NiTi alloy; M-Wire; CM-Gold Wire; CM-Blue Wire

\section{Introduction}

Endodontic rotary files have experienced continuous development since nickel-titanium (NiTi) files were introduced in the 1980s [1]. This alloy improved the flexibility and strength properties of endodontic rotary files compared with conventional stainless-steel endodontic instruments [2], and it simplified the treatment of root canals by improving the speed, accuracy, and safety of root canal shaping [3]. Despite continuous enhancements in the design and manufacture of NiTi endodontic rotary files to reduce the occurrence of complications during root canal treatment [4], failures remain a concern. Machado et al. retrospectively reported a fracture incidence of ProTaper Universal endodontic rotary files of $4.4 \%$ in 1031 teeth, mainly in mandibular first $(8.8 \%)$ and second (9.6\%) molars [5]; however, Bueno et al. reported no fractures in any of the 1104 Wave One Gold endodontic reciprocating files [6]. The more martensitic crystalline structure of the NiTi alloy of Wave One Gold endodontic 
reciprocating files allows higher flexibility and resistance than conventional austenitic endodontic rotary files. In addition, the removal of fractured fragments from NiTi endodontic rotary files within the root canal system is a challenge for the clinician because it prevents the disinfection of the entire root canal system [7].

Many variables can contribute to NiTi endodontic rotary file separation, such as root canal shape, instrument geometry, rotational speed, torque, sterilization cycles, the number of clinical uses, and the angle and radius of the curvature of the root canal system; however, researchers have focused their attention on the NiTi alloys, new surface treatments, and design improvements as prominent factors in the fracture resistance of NiTi endodontic rotary files [8-11]. Therefore, the surface treatments such as electropolishing, ion implantation, cryogenic treatment, and heat treatments improve the physical properties of NiTi endodontic rotary files, increasing their cyclic fatigue resistance [12]. Currently, the most widely used surface treatment is heat treatment, which consists of heat treating the NiTi alloy in a temperature range of around $450-550{ }^{\circ} \mathrm{C}$ and is carried out during or after the NiTi endodontic rotary file manufacturing process [12].

NiTi endodontic rotary systems are classified according to the crystal structure of the NiTi alloy: conventional NiTi, NiTi M-Wire, and R-Phase alloy endodontic rotary systems composed of an austenitic crystal structure, NiTi CM-Wire alloy endodontic rotary instruments composed of a martensitic crystal structure, and finally NiTi endodontic rotary systems that contain both austenitic and martensitic crystal structures [12]. Currently, novel endodontic rotary systems are developed with a higher concentration of the martensitic phase to improve the physical properties of hyperelasticity, shape memory, and fracture resistance compared to conventional NiTi alloys [12,13]. Conventional NiTi alloy of ProTaper Universal endodontic rotary files have lower cyclic fatigue resistance of endodontic rotary files compared to NiTi M-Wire of ProTaper Next endodontic rotary files [14-18]. Furthermore, NiTi CM-Wire alloy of Profile Vortex Blue and ProTaper Gold endodontic rotary files have shown a significantly $(p<0.05)$ higher cyclic fatigue resistance compared to the NiTi M-Wire alloy of endodontic rotary files $[17,19-23]$.

The purpose of the present study was to analyze and compare the effect of the NiTi alloy on the static cyclic fatigue resistance of NiTi endodontic rotary files, with a null hypothesis $\left(\mathrm{H}_{0}\right)$ stating that NiTi alloy of the endodontic rotary files would have no effect on the static cyclic fatigue resistance of NiTi endodontic rotary files.

\section{Materials and Methods}

\subsection{Study Design}

One hundred and sixty-four (164) sterile unused endodontic rotary files with a $250 \mu \mathrm{m}$ apical diameter were used in this in vitro study. All NiTi endodontic rotary files were first inspected under magnification (OPMI pico, Zeiss, Oberkochen, Germany), and none were discarded. A controlled experimental trial was performed at the Department of Stomatology of the Faculty of Medicine and Dentistry at the University of Valencia (Valencia, Spain), between September 2019 and July 2020. The NiTi endodontic rotary files were categorized into the following study groups: A: 25.08 F2 conventional NiTi alloy ProTaper Universal (Dentsply Maillefer, Baillagues, Switzerland) (PTU) ( $n=41)$; B: 25.06 X2 NiTi M-Wire alloy ProTaper Next (Dentsply Maillefer, Baillagues, Switzerland) (PTN) $(n=41)$; C: 25.08 F2 NiTi CM-Gold Wire alloy ProTaper Gold (Dentsply Maillefer, Baillagues, Switzerland) (PTG) ( $n=41)$; and D: 25.06 NiTi CM-Blue Wire alloy ProFile Vortex Blue (Dentsply Tulsa Dental, Tulsa, OK, USA) (PVB) $(n=41)$.

\subsection{Experimental Cycling Fatigue Procedure}

Static fatigue procedures were performed through the cyclic fatigue device previously described [24-26] and based on the cyclic fatigue device developed by Plotino et al. [27]. The 16:1 reduction handpiece (X-Smart Plus, Dentsply Maillefer, Baillagues, Switzerland) was placed and fixed 
on a square polymethyl methacrylate structure using four fixations and the artificial root canals systems were placed in a square polymethyl methacrylate structure fixed by two fixations to the previous polymethyl methacrylate structure (Figure 1).

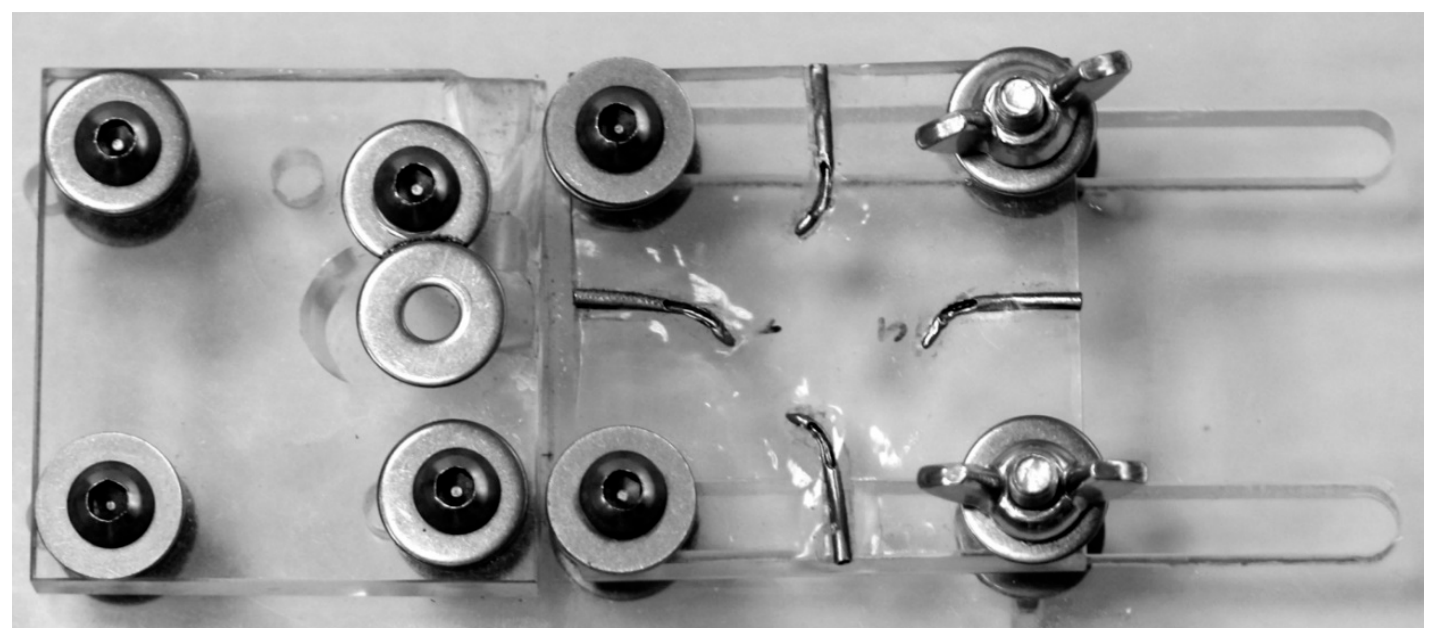

Figure 1. Static cyclic fatigue device with embedded stainless steel artificial root canal systems.

Two artificial root canal systems were constructed with $250 \mu \mathrm{m}$ apical diameter, $60^{\circ}$ curvature angle, $5 \mathrm{~mm}$ radius of curvature, $20 \mathrm{~mm}$ length, and $8 \%$ (25.08) (Figure 2A) and 6\% taper (25.06) (Figure 2B). The artificial root canal systems were formed from a stainless-steel cylinder (Cocchiola S.A., Buenos Aires, Argentina) based on the anatomy of each NiTi endodontic rotary file to ensure an intimate contact between the artificial root canal system walls and the NiTi endodontic rotary files. The stainless-steel artificial root canal systems were partially removed to allow the identification of the exact time to failure of the tested endodontic rotary instruments (Figure 2A,B). Furthermore, all the static fatigue procedures were filmed to allow the measurement of the exact time to failure. The NiTi endodontic rotary files were placed inside the artificial root canal systems at their full working length before the static fatigue test started (Figure 2A,B).
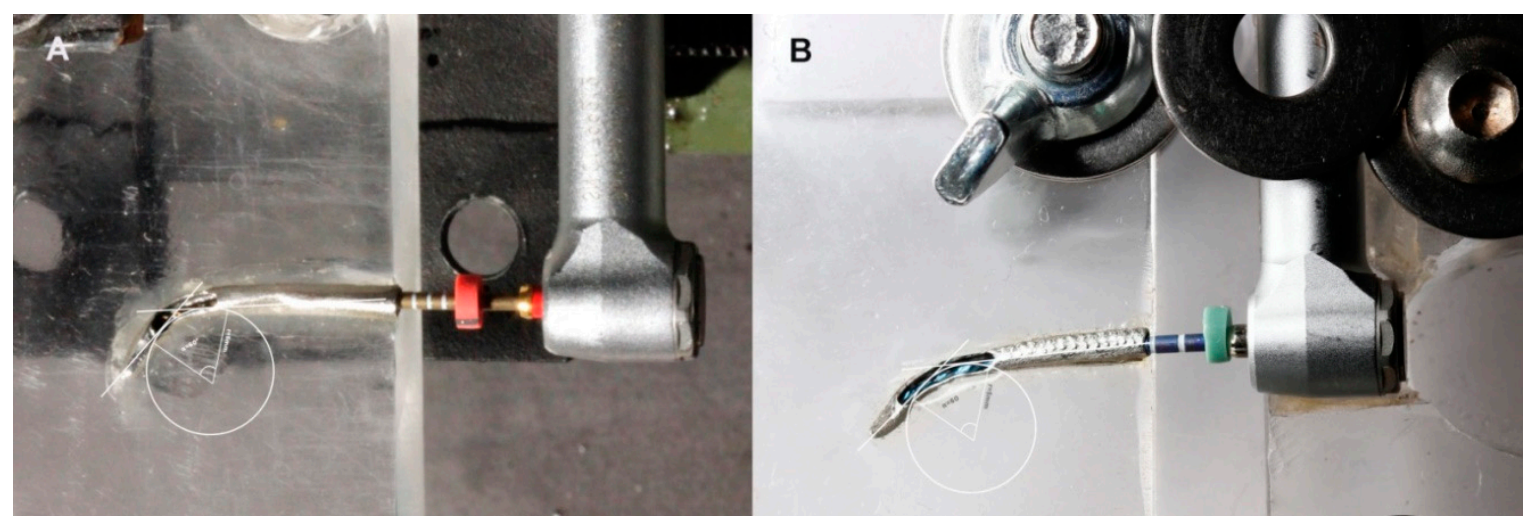

Figure 2. (A) ProTaper Gold (PTG) endodontic rotary file inside the $8 \%$ taper artificial root canal system and (B) ProFile Vortex Blue (PVB) endodontic rotary file inside the 6\% taper artificial root canal system.

The NiTi endodontic rotary files were used with a 16:1 reduction handpiece (X-Smart Plus, Dentsply Maillefer, Baillagues, Switzerland) according to the manufacturer's instructions. The PTU, PTN and PTG endodontic rotary files were used at 300 revolutions per minute $(\mathrm{rpm})$ and $5.2 \mathrm{~N} / \mathrm{cm}$ torque; however, PVB endodontic rotary files were used at $500 \mathrm{rpm}$ and $2.8 \mathrm{~N} / \mathrm{cm}$ torque. The NiTi endodontic rotary files were used until fracture occurred in order to analyze the time to failure and 
the number of cycles to failure were measured and recorded with a digital chronometer (Timex, Middlebury, CT, USA).

To reduce the friction between the reciprocating files and the artificial canal walls, high-flow synthetic oil designed for the lubrication of the artificial root canal systems (Singer All-Purpose Oil; Singer Corp., Barcelona, Spain) was applied [28,29].

\subsection{Scanning Electron Microscopy and Energy Dispersive X-ray Spectroscopy Analysis}

A Scanning Electron Microscopy (SEM) and an Energy Dispersive X-Ray Spectroscopy (EDX) analysis were performed in the Department of Mechanical, Energetic, and Materials Engineering of the School of Industrial Engineering of the University of Extremadura (Badajoz, Spain) to perform a surface characterization and analyze the elemental composition of the chemical elements of the NiTi endodontic rotary files used in the static fatigue tests by means of the atomic weight percent measurement at three different locations (1, 2 and 3). SEM analysis (HITACHI S-4800, Fukuoka, Japan) of the NiTi endodontic rotary files was performed with the following exposure parameters: acceleration voltage: $20 \mathrm{kV}$, magnification from $100 \times$ to $6500 \times$ and a resolution between $-1.0 \mathrm{~nm}$ at $15 \mathrm{kV}$ and $2.0 \mathrm{~nm}$ at $1 \mathrm{kV}$.

\subsection{Statistical Tests}

Statistical analysis was performed by means of SAS 9.4 (SAS Institute Inc., Cary, NC, USA). Descriptive analysis included the mean and standard deviation (SD) for quantitative data. Comparative statistics was carried out by comparing the time to failure (minutes) and the number of cycles to failure using the ANOVA test. Weibull statistical analysis was also conducted. Descriptive analysis of the SEM and EDX analysis of the endodontic rotary files was also described. Statistical significance level was established at $p<0.05$.

\section{Results}

The mean and SD values for time to failure (minutes) for each of the study groups are displayed in Table 1 and Figure 3.

Table 1. Descriptive analysis of the time to failure (minutes).

\begin{tabular}{cccccc}
\hline Study Group & $\boldsymbol{n}$ & Mean & SD & Minimum & Maximum \\
\hline PTU & 41 & $1.24^{\mathrm{a}}$ & 0.21 & 0.33 & 1.58 \\
PTN & 41 & $2.63^{\mathrm{b}}$ & 0.58 & 1.83 & 4.20 \\
PTG & 41 & $3.42^{\mathrm{c}}$ & 0.85 & 1.68 & 5.89 \\
PVB & 41 & $2.86^{\mathrm{b}}$ & 0.82 & 1.41 & 4.89 \\
\hline
\end{tabular}

$a, b, c$ Statistically significant differences between groups $(p<0.05)$. PTU: ProTaper Universal; PTN: ProTaper Next; PTG: ProTaper Gold; PVB: ProFile Vortex Blue.

The ANOVA analysis showed statistically significant differences between time to failure of PTG and PTN $(p<0.001)$, PTG and PTU $(p<0.001)$, PTG and PVB $(p=0.001)$, PTN and PTU $(p<0.001)$, and PTU and PVB $(p<0.001)$ NiTi endodontic rotary file study groups (Figure 3$)$. However, no statistically significant differences were observed between time to failure of PTN and PVB ( $p=0.379)$ (Figure 3). 


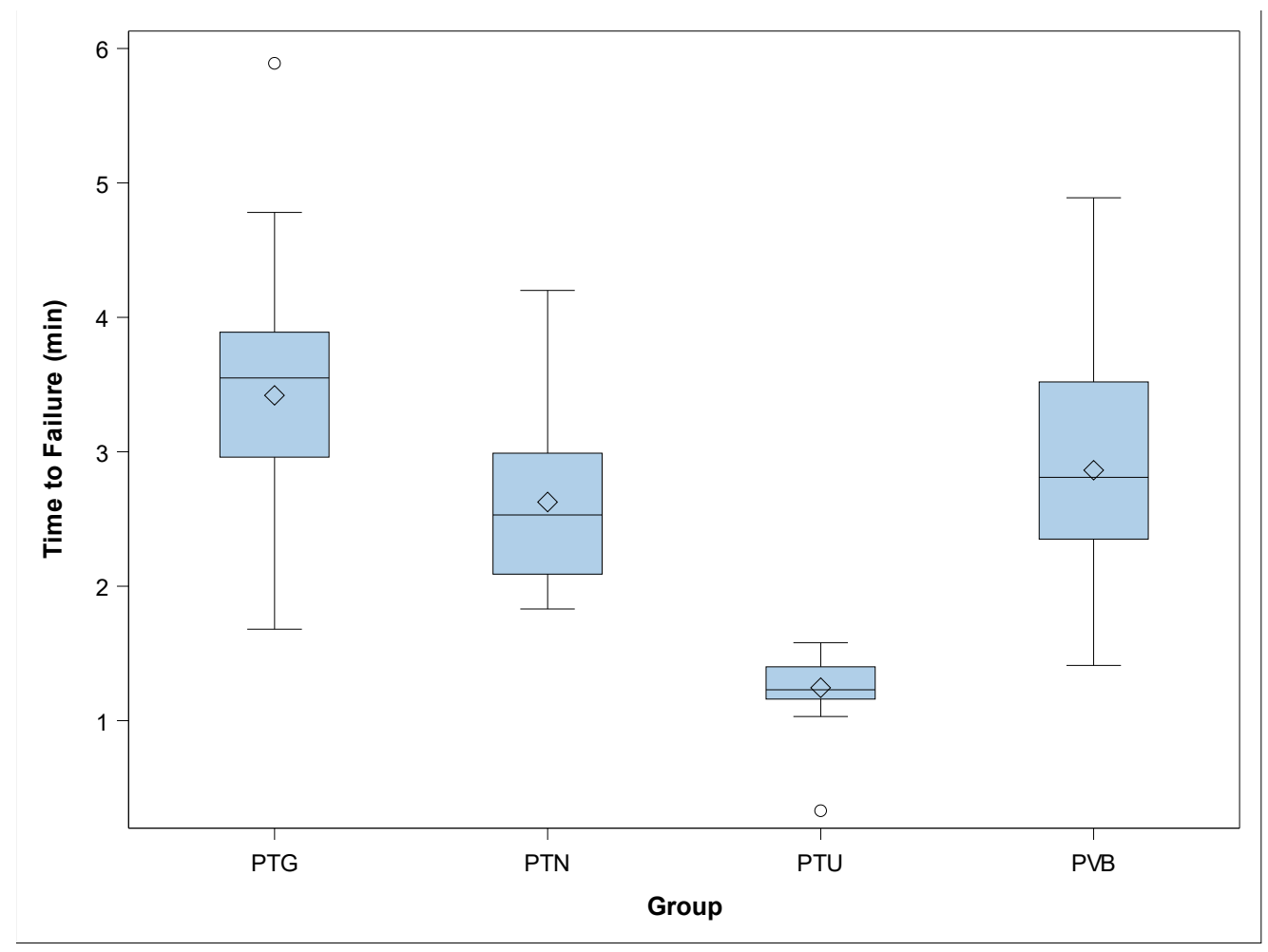

Figure 3. Box plot of the time to failure. The horizontal line in each box represents the respective median value of the study groups. $\diamond$; Mean value of the box plots. PTU: ProTaper Universal; PTN: ProTaper Next; PTG: ProTaper Gold; PVB: ProFile Vortex Blue.

The scale distribution parameter $(\eta)$ of Weibull statistics found statistically significant differences between the time to failure of PTG and PVB $(p=0.003)$, PTU and PVB $(p<0.001)$, PTG and PTU $(p<0.001)$, PTN and PTU $(p<0.001)$, and PTG and PVB $(p<0.001)$ NiTi endodontic rotary files (Table 2, Figure 4); however, there were no statistically significant differences between the time to failure of PTN and PVB $(p=0.067)$ NiTi endodontic rotary file study groups (Table 2, Figure 4$)$. The shape distribution parameter $(\beta)$ of Weibull statistics found statistically significant differences between the time to failure of PTU and PVB $(p<0.001)$, PTG and PTU $(p=0.001)$, and PTN and PTU $(p=0.003)$ NiTi endodontic rotary files (Table 2, Figure 4). However, no statistically significant differences were observed between the time to failure of PTG and PVB $(p=0.467)$, PTN and PVB $(p=0.228)$, and PTG and PVB $(p=0.628)$ (Table 2, Figure 4$)$ study groups. Briefly, the behavior of the endodontic rotary systems was very predictable, because most endodontic rotary files of each endodontic rotary system fractured at almost the same time. The less-steep slope generated by PTU NiTi endodontic rotary files indicates that the behavior is more predictable than in the other endodontic rotary systems, but they fracture earlier. The PTG NiTi endodontic rotary files showed a higher cyclic fatigue resistance than the PTU, PTN, and PVB NiTi endodontic rotary files.

Table 2. Weibull statistics of time to failure of the study groups.

\begin{tabular}{ccccccccc}
\hline \multirow{2}{*}{ Study Group } & \multicolumn{3}{c}{ Weibull Shape $(\beta)$} & \multicolumn{4}{c}{ Weibull Scale $(\eta)$} \\
\cline { 2 - 9 } & Estimate & St Error & Lower & Upper & Estimate & St Error & Lower & Upper \\
\hline PTU & 7.7054 & 0.9453 & 6.0585 & 9.8000 & 1.3203 & 0.0279 & 1.2666 & 1.3762 \\
PTN & 4.7196 & 0.5369 & 3.7764 & 5.8983 & 2.8604 & 0.1005 & 2.6701 & 3.0643 \\
PTG & 4.3641 & 0.5001 & 3.4862 & 5.4632 & 3.7429 & 0.1414 & 3.4758 & 4.0307 \\
PVB & 3.8689 & 0.4629 & 3.0601 & 4.8914 & 3.1652 & 0.1350 & 2.9114 & 3.4410 \\
\hline
\end{tabular}




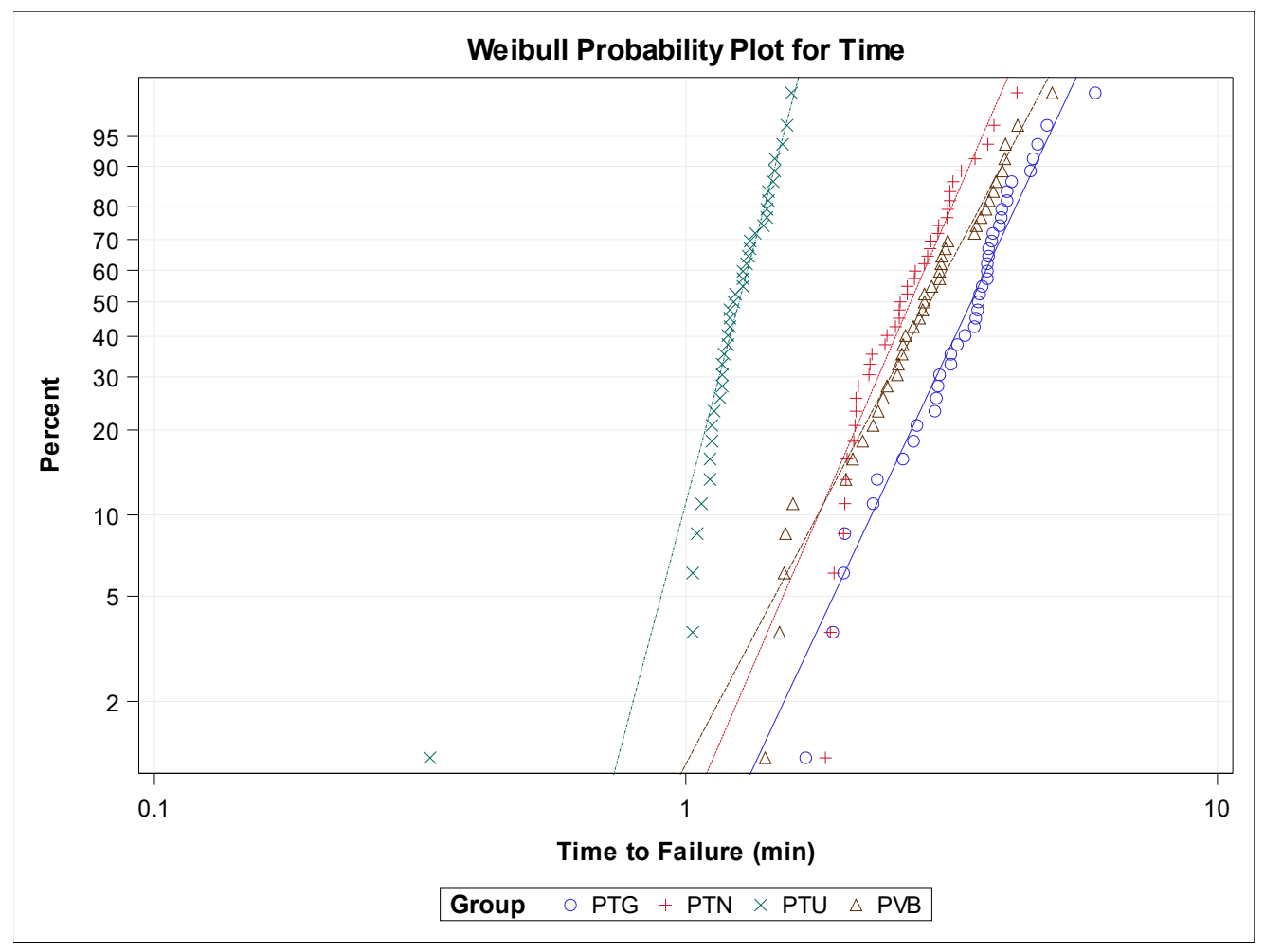

Figure 4. Weibull probability plot of time to failure for the study groups.

The mean and SD values for number of cycles to failure for each of the study groups are displayed in Table 3 and Figure 5.

Table 3. Descriptive statistics of the number of cycles to failure of the study groups.

\begin{tabular}{cccccc}
\hline Study Group & $n$ & Mean & SD & Minimum & Maximum \\
\hline PTU & 41 & $373.46^{\mathrm{a}}$ & 62.40 & 99.00 & 474.00 \\
PTN & 41 & $787.90^{\mathrm{b}}$ & 173.91 & 549.00 & 1260.00 \\
PTG & 41 & $1021.49^{\mathrm{c}}$ & 264.81 & 415.00 & 1767.00 \\
PVB & 41 & $1431.46^{\mathrm{d}}$ & 411.60 & 705.00 & 2445.00 \\
\hline \multicolumn{5}{c}{ a,b,c,d Statistically significant differences between groups $(p<0.05)}$.
\end{tabular}

The ANOVA analysis showed statistically significant differences between the number of cycles to failure of PTG and PTN $(p=0.001)$, PTG and PTU $(p<0.001)$, PTG and PVB $(p<0.001)$, PTN and PTU $(p<0.001)$, PTN and PVB $(p<0.001)$, and PTU and PVB $(p<0.001)$ NiTi endodontic rotary file study groups (Figure 5). 


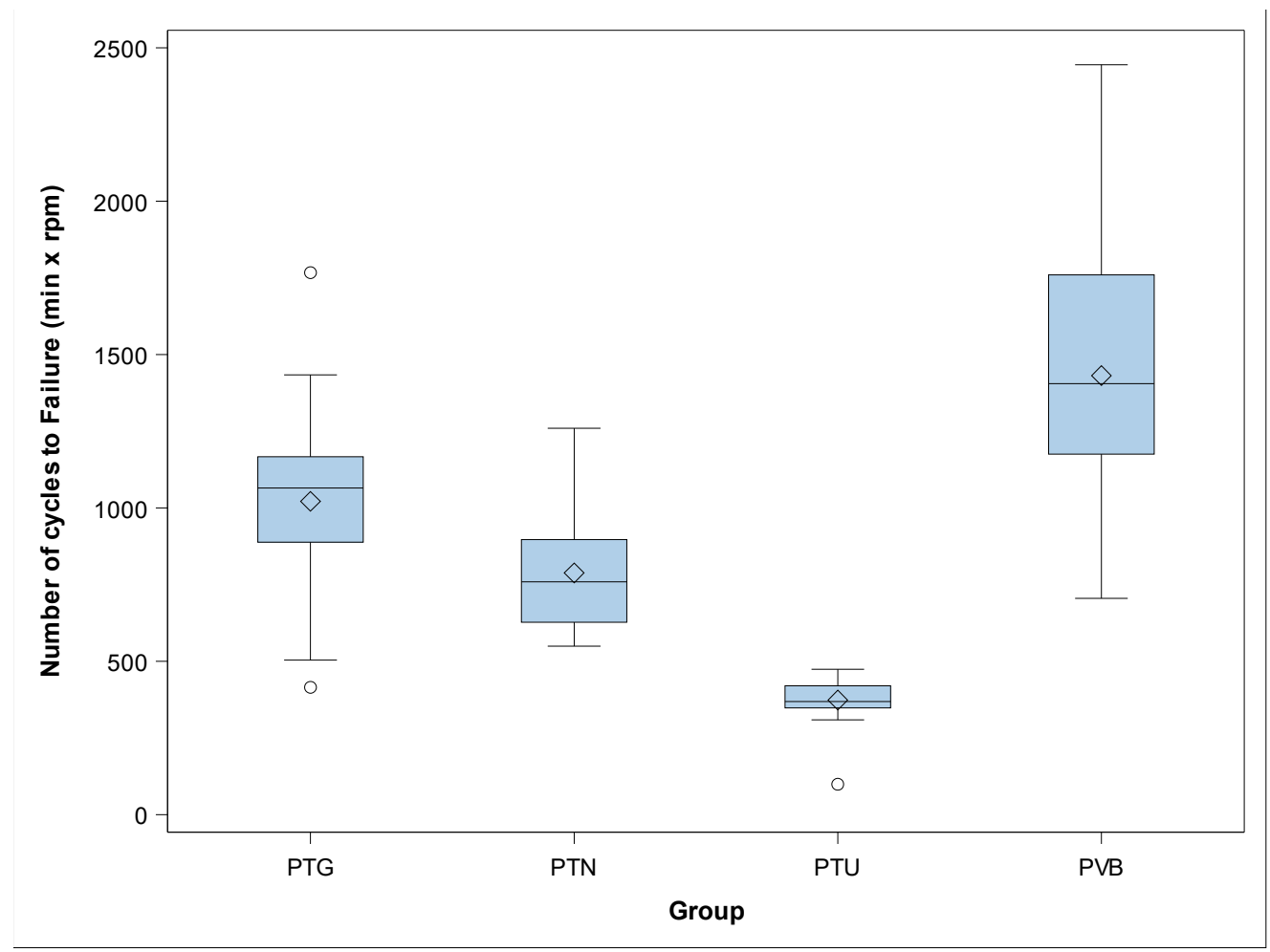

Figure 5. Box plot of the number of cycles to failure. The horizontal line in each box represents the respective median value of the study groups. $\bigcirc$ : Mean value of the box plots.

The scale distribution parameter $(\eta)$ of Weibull statistics found statistically significant differences between the number of cycles to failure of PTG and PVB $(p<0.001)$, PTN and PVB $(p<0.001)$, PTU and PVB $(p<0.001)$, PTG and PTU $(p<0.001)$, PTN and PTU $(p<0.001)$, and PTG and PVB $(p<0.001)$ NiTi endodontic rotary files (Table 4, Figure 6). The shape distribution parameter ( $\beta$ ) of the Weibull statistics found statistically significant differences between the number of cycles to failure of PTU and PVB $(p<0.001)$, PTG and PTU $(p<0.001)$, and PTN and PTU $(p=0.003)$ NiTi endodontic rotary files (Table 4, Figure 6). However, no statistically significant differences were observed between the number of cycles to failure of PTG and PVB $(p=0.557)$, PTN and PVB $(p=0.228)$, and PTG and PVB $(p=0.535)$ (Table 4, Figure 6). Briefly, the behavior of the endodontic rotary systems is very predictable, because most endodontic rotary files of each endodontic rotary system break almost at the same time. The less steep slope generated by PTU NiTi endodontic rotary files indicates that the behavior is more predictable than in the other endodontic rotary systems, but they fracture earlier. The PVB NiTi endodontic rotary files showed a higher cyclic fatigue resistance than did the PTU, PTN, and PTG NiTi endodontic rotary files.

Table 4. Weibull statistics of the number of cycles to failure for the study groups.

\begin{tabular}{ccccccccc}
\hline Study Group & \multicolumn{3}{c}{ Weibull Shape $(\boldsymbol{\beta})$} & \multicolumn{4}{c}{ Weibull Scale $(\eta)$} \\
\hline & Estimate & St Error & Lower & Upper & Estimate & St Error & Lower & Upper \\
\hline PTU & 7.7054 & 0.9453 & 6.0585 & 9.8000 & 396.0883 & 8.3847 & 379.9908 & 412.8678 \\
PTN & 4.7196 & 0.5369 & 3.7764 & 5.8983 & 858.1237 & 30.1478 & 801.0235 & 919.2942 \\
PTG & 4.2673 & 0.4950 & 3.3995 & 5.3566 & 1119.912 & 43.1923 & 1038.377 & 1207.8487 \\
PVB & 3.8689 & 0.4629 & 3.0601 & 4.8914 & 1582.588 & 67.4766 & 1455.711 & 1720.5229 \\
\hline
\end{tabular}




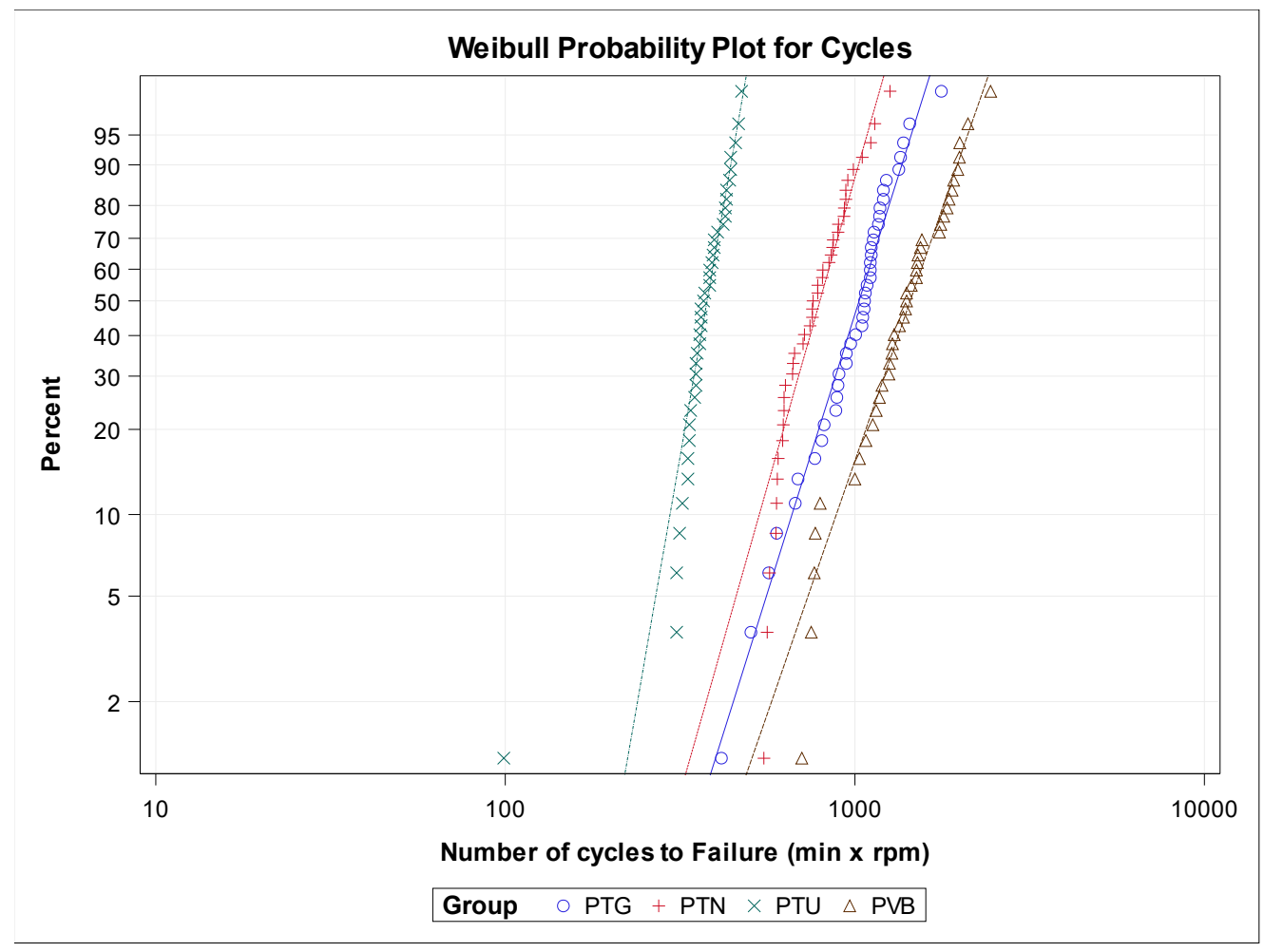

Figure 6. Weibull probability plot of the number of cycles to failure for the study groups.

SEM analysis of the NiTi alloy PTU endodontic rotary files did not show accumulation of organic matter or structural alterations. Furthermore, manufacturing lines were distributed perpendicularly to the longitudinal axis of the endodontic rotary files and also parallel to each other due to the laser machining manufacturing process. The width and distance between the manufacturing lines corresponded to the precision and intensity of the laser machining process. Tubular porosity due to the laser machining process was also observed. Furthermore, all NiTi alloy PTU endodontic rotary files exhibited tubular porosity resulting from the combination of Ti alloys with other chemicals elements (Figure 7A-C).
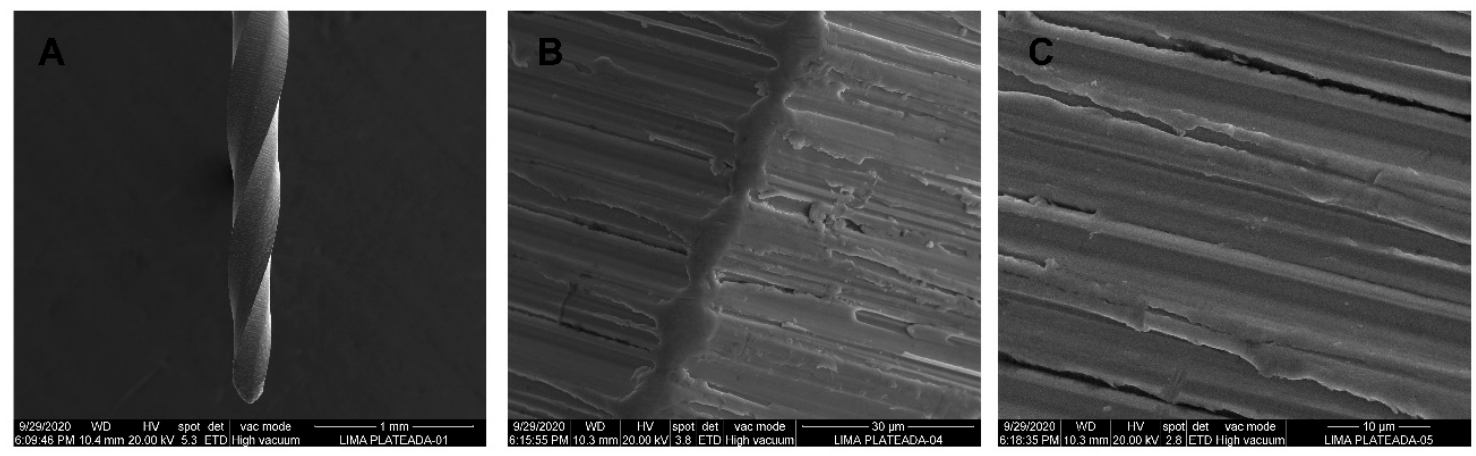

Figure 7. SEM images of NiTi alloy ProTaper Universal (PTU) endodontic rotary files at (A) 100×, (B) $3600 \times$, and (C) $6500 \times$.

EDX micro-analysis of PTU, PTN, PTG, and PVB NiTi endodontic rotary files was performed at $20 \mathrm{kV}$ at three different locations, which allowed for a deep and accurate analysis of the NiTi endodontic rotary files composition. EDX micro-analysis at $20 \mathrm{kV}$ showed that PTU NiTi endodontic rotary files were composed of C (2.17-3.18 wt.\%), O (1.48-1.61 wt.\%), Ti (42.72-43.25 wt.\%), and Ni (52.56-52.97 wt.\%) (Table 5 and Figure 8A-C). 
Table 5. Mean atomic weight percent (\%) of NiTi alloy PTU endodontic rotary files at $15 \mathrm{kV}$ and $20 \mathrm{kV}$ and three different locations $(1,2$ and 3$)$.

\begin{tabular}{ccccc}
\hline Spectrum & C & O & Ti & Ni \\
\hline PTU 20 kV (1) & 2.17 & 1.61 & 43.25 & 52.97 \\
PTU 20 kV (2) & 3.18 & 1.54 & 42.72 & 52.56 \\
PTU 20 kV (3) & 2.65 & 1.48 & 42.99 & 52.87 \\
Sigma & 0.55 & 0.65 & 0.46 & 0.53 \\
\hline
\end{tabular}
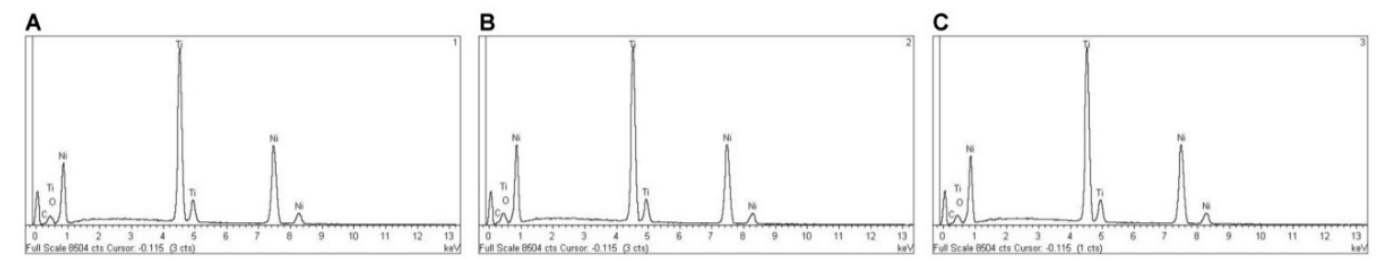

Figure 8. EDX micro-analysis of NiTi alloy PTU endodontic rotary files in location (A) 1, (B) 2, and (C) 3 .

SEM analysis of the NiTi M-Wire alloy PTN endodontic rotary files did not show accumulation of organic matter or structural alterations. Furthermore, manufacturing lines were distributed perpendicularly to the longitudinal axis of the endodontic rotary files and also parallel to each other due to the laser machining manufacturing process. Lower width and distance between the manufacturing lines was observed compared to the NiTi alloy PTU endodontic rotary files. Tubular porosity due to the laser machining process was also observed (Figure 9A-C).
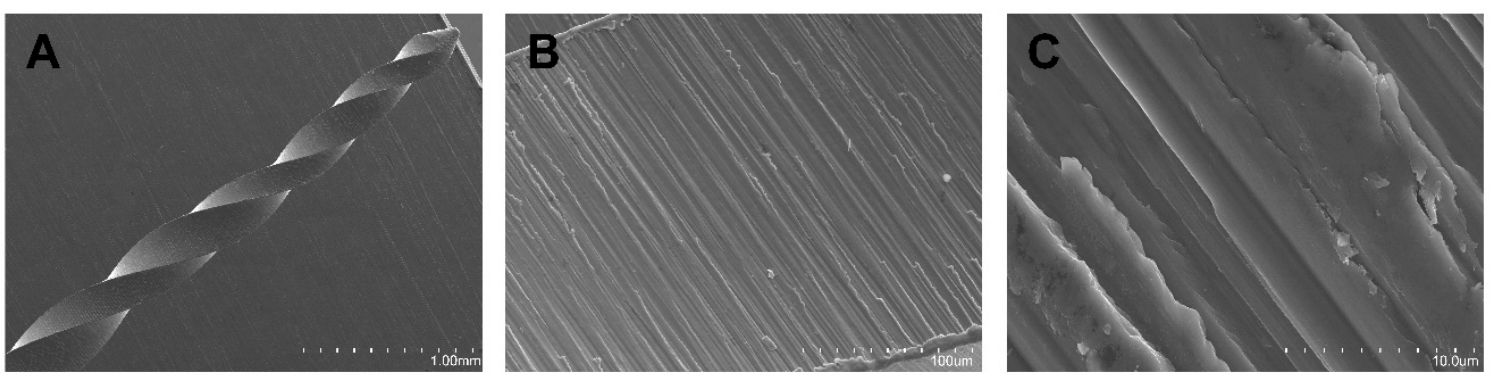

Figure 9. SEM images of M-Wire alloy ProTaper Next (PTN) endodontic rotary files at (A) 100×,

(B) $3600 \times$, and (C) $6500 \times$.

EDX micro-analysis at $20 \mathrm{kV}$ in three different locations showed that M-Wire alloy PTN endodontic rotary files were composed of C (3.31-4.43 wt.\%), Al (0.56-1.39 wt.\%), Ti (50.39-51.03 wt.\%), and Ni (43.31-45.10 wt.\%) (Table 6 and Figure 10A-C).

Table 6. Mean atomic weight percent (\%) of M-Wire alloy PTN endodontic rotary files at $15 \mathrm{kV}$ and 20 $\mathrm{kV}$ and three different locations $(1,2$, and 3$)$.

\begin{tabular}{ccccc}
\hline Spectrum & C & Al & Ti & Ni \\
\hline PTN 20 kV (1) & 4.43 & 1.24 & 51.03 & 43.31 \\
PTN 20 kV (2) & 3.31 & 1.39 & 50.39 & 44.90 \\
PTN 20 kV (3) & 3.43 & 0.56 & 50.91 & 45.10 \\
Sigma & 0.61 & 0.44 & 0.34 & 0.98 \\
\hline
\end{tabular}



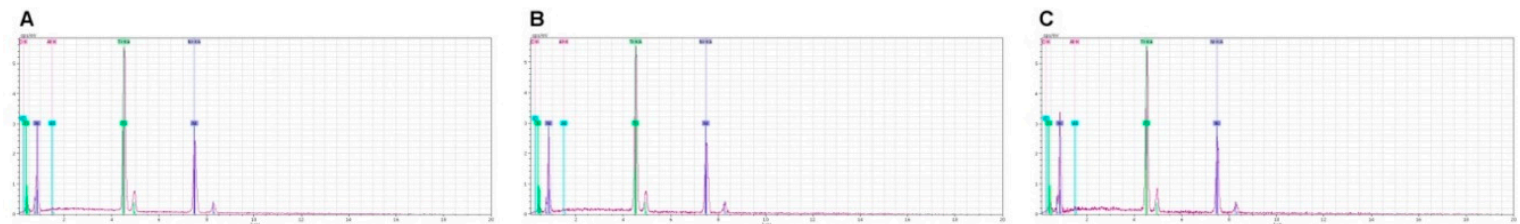

Figure 10. EDX micro-analysis of M-Wire alloy PTN endodontic rotary files at locations (A) 1, (B) 2, and $(\mathbf{C}) 3$.

SEM analysis of the NiTi CM-Gold Wire alloy PTG endodontic rotary files did not show accumulation of organic matter or structural alterations. Furthermore, manufacturing lines were distributed perpendicularly to the longitudinal axis of the endodontic rotary files and also parallel to each other due to the laser machining manufacturing process (Figure 11A-C).
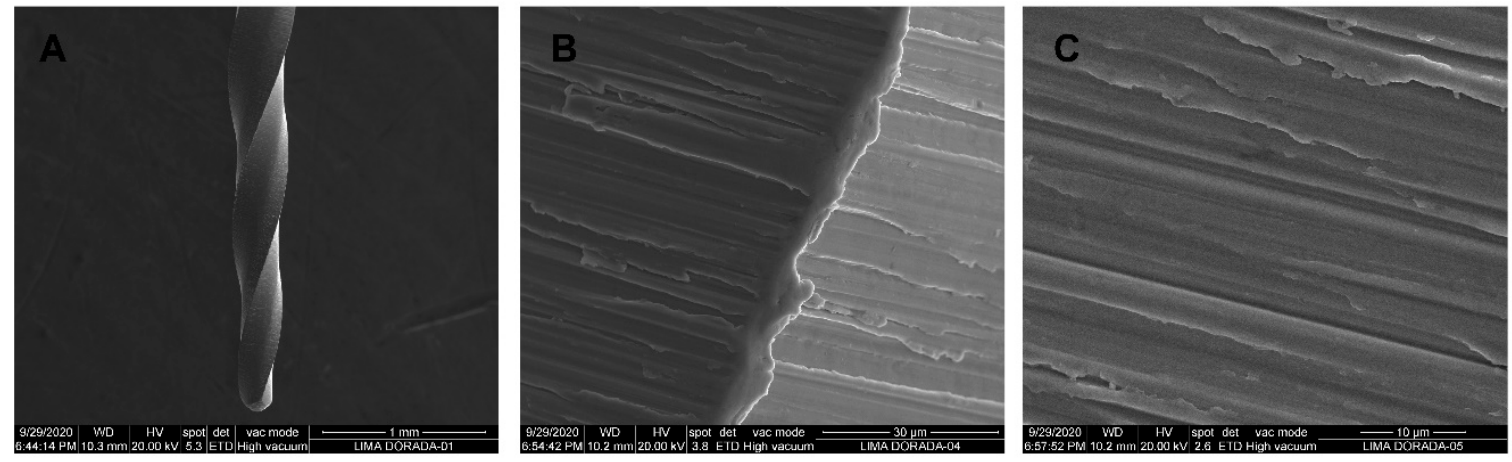

Figure 11. SEM images of CM-Gold Wire alloy PTG endodontic rotary files at (A) 100×, (B) 3600×, and (C) $6500 \times$.

EDX micro-analysis at $20 \mathrm{kV}$ in three different locations showed that CM-Gold Wire PTG endodontic rotary files were composed of C (2.11-2.20 wt.\%), O (6.87-7.54 wt.\%), Ti (40.49-40.82 wt.\%), and $\mathrm{Ni}$ (49.59-50.20 wt.\%) (Table 7 and Figure 12A-C).

Table 7. Mean atomic weight percent (\%) of CM-Gold Wire alloy PTG endodontic rotary files at $15 \mathrm{kV}$ and $20 \mathrm{kV}$ at three different locations (1,2 and 3).

\begin{tabular}{ccccc}
\hline Spectrum & C & O & Ti & Ni \\
\hline PTG 20 kV (1) & 2.11 & 6.87 & 40.82 & 50.20 \\
PTG 20 kV (2) & 2.12 & 7.35 & 40.49 & 50.04 \\
PTG 20 kV (3) & 2.20 & 7.54 & 40.67 & 49.59 \\
Sigma & 0.54 & 0.67 & 0.44 & 0.53 \\
\hline
\end{tabular}
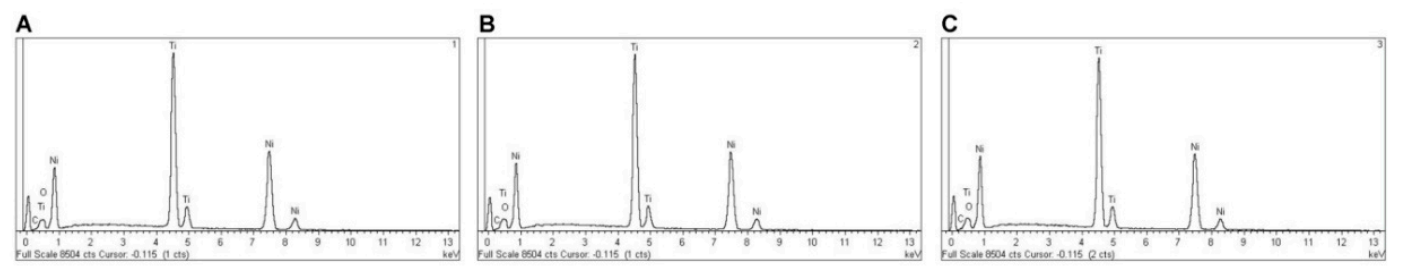

Figure 12. EDX micro-analysis of CM-Gold Wire PTG endodontic rotary files in location (A) 1, (B) 2, and $(\mathbf{C}) 3$.

SEM analysis of the CM-Blue Wire alloy PVB endodontic rotary files did not show accumulation of organic matter or structural alterations. Furthermore, manufacturing lines were distributed 
perpendicularly to the longitudinal axis of the endodontic rotary files and also parallel to each other due to the laser machining manufacturing process (Figure 13A-C).
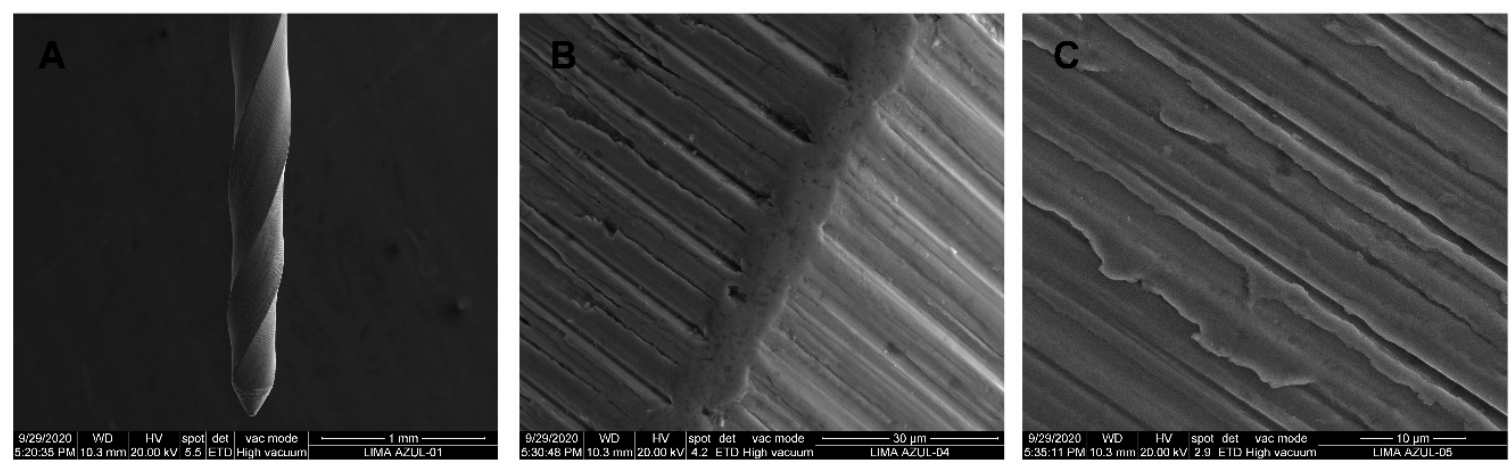

Figure 13. SEM images of CM-Blue Wire PVB endodontic rotary files at (A) $100 \times$, (B) $3600 \times$, and (C) $6500 \times$.

EDX micro-analysis at $20 \mathrm{kV}$ at three different locations showed that CM-Blue Wire PVB NiTi endodontic rotary files were composed of C (2.26-2.71 wt.\%), O (11.37-13.30 wt.\%), Ti (37.87-38.98 wt.\%), and Ni (46.17-47.56 wt.\%) (Table 8, Figure 14A-C).

Table 8. Mean atomic weight percent (\%) of CM-Blue Wire PVB endodontic rotary files at $15 \mathrm{kV}$ and 20 $\mathrm{kV}$ at three different locations $(1,2$ and 3$)$.

\begin{tabular}{ccccc}
\hline Spectrum & C & O & Ti & Ni \\
\hline PVB 20 kV (1) & 2.66 & 13.30 & 37.87 & 46.17 \\
PVB 20 kV (2) & 2.26 & 11.80 & 38.38 & 47.56 \\
PVB 20 kV (3) & 2.71 & 11.37 & 38.98 & 46.94 \\
Sigma & 0.58 & 0.69 & 0.44 & 0.53 \\
\hline
\end{tabular}
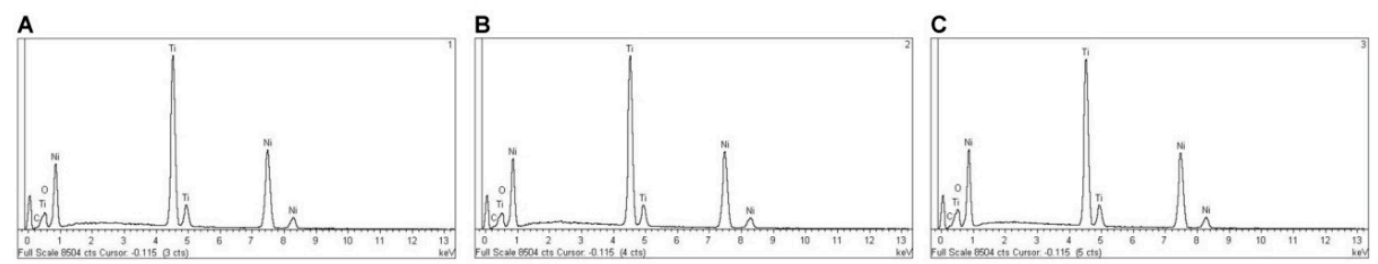

Figure 14. EDX micro-analysis of CM-Blue Wire PVB endodontic rotary files at locations (A) 1, (B) 2, and (C) 3 .

\section{Discussion}

The results obtained in the present study reject the null hypothesis $\left(\mathrm{H}_{0}\right)$ that states that the NiTi alloy of the endodontic rotary files has no effect on the static cyclic fatigue resistance of NiTi endodontic rotary files.

NiTi endodontic rotary files suffer unexpected fractures inside the root canal system despite their greater flexibility $[4,30]$, which are produced by the stress caused by cyclic fatigue, torsional fatigue, or a combination of both $[31,32]$. The incidence of fracture of NiTi endodontic rotary files ranges from $0.09 \%$ to $5 \%[33,34]$ and influences the prognosis of the root canal system as the fractured fragment blocks the access to the apex, preventing disinfection of the root canal system. Furthermore, it has been reported that the presence of a previous periapical pathology combined with the fracture of an endodontic instrument represents a significant decrease in the success of the root canal treatment [35]. This is the reason why the cyclic fatigue resistance of NiTi endodontic rotary files has been widely analyzed. 
In 2002, the American National Standard Institute and the American Dental Association established a standardization procedure to assess the cyclic and torsional fatigue resistance of stainless steel endodontic hand files [36]. The fatigue resistance was also described by the International Standards Organization (ISO) (ISO 3630/1) for 2\% taper stainless steel endodontic hand files [37]; however, no specifications for the cyclic fatigue resistance of NiTi endodontic rotary systems above $2 \%$ taper exist, so many different static and dynamic cyclic fatigue devices have been developed to analyze the cyclic fatigue resistance of NiTi endodontic rotary files. A static cyclic fatigue device was used for this study because it allowed the analysis of an accumulative stress concentration located in the curvature area of the artificial root canal system that caused microstructural changes in the NiTi alloy responsible for the cyclic fatigue resistance of NiTi endodontic rotary files [38]. However, the static cyclic fatigue resistance comparison of different $\mathrm{NiTi}$ endodontic rotary systems is highly complicated due to difficulty in isolating its differences while respecting transversal designs, tapers, angular speeds, and NiTi alloy. For this reason, the most similar files for each endodontic rotary system were selected based on their length, apical diameter, cross section, angular movement, and speed and taper, although this represents a limitation within the study. In addition, the different speed values at which the NiTi endodontic rotary systems were used could influence the study results, but the NiTi endodontic rotary systems were used at the speed values recommended by the manufacturers. PTU, PTN, and PTG NiTi endodontic rotary systems were used at $300 \mathrm{rpm}$, while the PVB NiTi endodontic rotary system was used at $500 \mathrm{rpm}$; however, most authors agree that rotation speed appears to have no effect on the resistance of NiTi endodontic rotary systems [32,39,40].Gao et al. showed no statistical significant differences $(p>0.05)$ between the NiTi endodontic rotary files made of the same NiTi alloy and the same apical diameter but operated at different rotation speeds to cyclic fatigue resistance [41].

Previous studies have also analyzed the influence of the NiTi alloy on the cyclic fatigue resistance of endodontic rotary files, and most agree that the martensitic phase of NiTi alloy is the crystalline structure most resistant to cyclic fatigue [42]. In this study, the comparison of the static cyclic fatigue resistance of conventional NiTi alloy of PTU endodontic rotary files (1.24 $\pm 0.21 \mathrm{~min})$ and NiTi M-Wire alloy of PTN endodontic rotary files $(2.63 \pm 0.58 \mathrm{~min})$ showed a significantly $(p<0.001)$ higher static cyclic fatigue resistance of PTN NiTi endodontic rotary files compared to PTU endodontic rotary files. In addition, the comparison between conventional NiTi alloy of PTU endodontic rotary files $(1.24 \pm 0.21 \mathrm{~min})$ and NiTi CM-Gold Wire alloy of PTG endodontic rotary files (3.42 $\pm 0.85 \mathrm{~min})$ was influenced by fewer variables compared to the rest of the NiTi endodontic rotary systems because they presented similar cross-sections and designs. These NiTi endodontic rotary systems showed a significantly $(p<0.001)$ higher static cyclic fatigue resistance for PTG NiTi endodontic rotary files than PTU endodontic rotary files, which highlights the influence of the NiTi alloy on the cyclic fatigue resistance of NiTi endodontic rotary files, as was already shown in previous studies [16,19]. Furthermore, the comparison between the NiTi CM-Gold Wire alloy of PTG endodontic rotary files $(3.42 \pm 0.85 \mathrm{~min})$ and the NiTi CM-Blue Wire alloy of PVB endodontic rotary files $(2.86 \pm 0.82 \mathrm{~min})$ also showed significantly $(p<0.001)$ higher static cyclic fatigue resistance of PTG NiTi endodontic rotary files than PVB endodontic rotary files; however, it is difficult to isolate the most relevant variable or the most determinant variable combination in cyclic fatigue resistance of NiTi endodontic rotary files. These results differ when comparing the cyclic fatigue resistance of the NiTi CM-Blue Wire alloy of Reciproc Blue endodontic reciprocating system with the NiTi CM-Gold Wire alloy from the Wave One Gold endodontic reciprocating system. The cyclic fatigue resistance of the Reciproc Blue endodontic reciprocating system showed a higher resistance to cyclic fatigue than the Wave One Gold endodontic reciprocating system, probably due to the cross-sectional design $[43,44]$. The influence of the cross-sectional design on the cyclic fatigue resistance was also analyzed by comparing the NiTi M-Wire alloy of the Reciproc endodontic reciprocating system with the NiTi M-Wire alloy of the Wave One endodontic reciprocating system and showed that the Reciproc endodontic reciprocating system had significantly $(p<0.001)$ higher static cyclic fatigue resistance than the Wave One endodontic reciprocating system [45]. 
The novel heat treatments of NiTi alloys show more resistance to cyclic fatigue than conventional NiTi alloys. Elanghy et al. reported a statistically significant $(p<0.001)$ higher cyclic fatigue resistance of ProTaper Next and ProTaper Gold compared to conventional NiTi alloys of TRUShape and ProTaper Universal NiTi endodontic rotary systems [46], and Uygun et al. reported similar results when comparing ProFile Vortex Blue and ProTaper Next with the conventional NiTi alloy of ProTaper Universal [47]. These results agreed with those obtained in the present study and highlight the relevance of the alloying elements in the allotropic transformation of the crystalline structure of the NiTi alloy, which in turn influences the physical and mechanical properties of the endodontic rotary files [47]. Titanium is an allotropic metal which can present two crystalline structures: compact hexagonal ( $\alpha$ or austenite) and body-centered cubic ( $\beta$ or martensite). Depending on the stabilizing effect of the $\alpha$ and $\beta$ phases, the alloying elements of titanium are classified as neutral elements, betagenic elements, or stabilizers of the $\alpha$ phase and alphagenic elements or stabilizers of the $\beta$ phase. The stabilization of the phases implies the increase or decrease of the transition temperature $\beta$ [48]; specifically, alphagenic elements increase the transition temperature $\beta$. Among the alphagenic elements, $\mathrm{Al}$ is the most important alloying element, although $\mathrm{O}, \mathrm{C}$, and $\mathrm{N}$ can also be used. The results obtained from the EDX micro-analysis showed the presence of the above mentioned alloying elements. The atomic weight of the alloying elements showed an upward trend from the conventional NiTi alloy of PTU endodontic rotary files (C (2.17-3.18 wt.\%) and O (1.48-1.61 wt.\%)), to the NiTi M-Wire alloy of PTN endodontic rotary files (C (3.31-4.43 wt.\%) and $\mathrm{Al}(0.56-1.39 \mathrm{wt} . \%))$, to the NiTi CM-Blue Wire alloy of PVB endodontic rotary files (C (2.26-2.71 wt.\%) and O (11.37-13.30 wt.\%)), and finally to the NiTi CM-Gold Wire alloy of PTG endodontic rotary files (C (2.11-2.20 wt.\%) and O (6.87-7.54 wt.\%)); this leads to more crystalline structures that are more martensitic and therefore more flexible and resistant to fracture, which is consistent with the time to failure observed in the study of resistance to static cyclic fatigue.

\section{Conclusions}

NiTi CM-Gold wire alloy of the ProTaper Gold endodontic rotary files is more resistance to cyclic fatigue than ProFile Vortex Blue, ProTaper Next, and ProTaper Universal endodontic rotary files, due to the elements of the alloy present in the crystalline structure that give the ProTaper Gold endodontic rotary files greater flexibility and resistance.

Author Contributions: All of the authors contributed to the investigation, supervision, writing, review, and editing of the study. Conceptualization, C.R.-S. and V.F.-L.; data curation, I.F.-M. and V.F.-M.; formal analysis, S.S.; visualization, Á.Z.-M. All authors have read and agreed to the published version of the manuscript.

Funding: This research received no external funding.

Conflicts of Interest: The authors declare no conflict of interest.

\section{References}

1. Gavini, G.; Santos, M.D.; Caldeira, C.L.; Machado, M.E.L.; Freire, L.G.; Iglecias, E.F.; Peters, O.A.; Candeiro, G.T.M. Nickel-titanium instruments in endodontics: A concise review of the state of the art. Braz. Oral Res. 2018, 32 (Suppl. 1), e67. [CrossRef] [PubMed]

2. Peralta-Mamani, M.; Rios, D.; Duarte, M.A.H.; Santiago Junior, J.F.; Honório, H.M. Manual vs. rotary instrumentation in endodontic treatment of permanent teeth: A systematic review and meta-analysis. Am. J. Dent. 2019, 32, 311-324. [PubMed]

3. Uslu, G.; Gundogar, M.; Özyurek, T.; Plotino, G. Cyclic fatigue resistance of reduced-taper nickel-titanium (NiTi) instruments in doubled-curved (S-shaped) canals at body temperature. J. Dent. Res. Dent. Clin. Dent. Prospects 2020, 14, 111-115. [CrossRef] [PubMed]

4. Bergmans, L.; van Cleynenbreugel, J.; Wevers, M.; Lambrechts, P. Mechanical root canal preparation with NiTi rotary instruments: Rationale, performance and safety. Status report for the American Journal of Dentistry. Am. J. Dent. 2001, 14, 324-333. [PubMed] 
5. Machado, R.; Júnior, C.S.; Colombelli, M.F.; Picolli, A.P.; Junior, J.S.; Cosme-Silva, L.; Garcia, L.D.F.R.; Alberton, L.R. Incidence of ProTaper Universal System Instrument Fractures-A Retrospective Clinical Study. Eur. Endod. J. 2018, 3, 77-81. [CrossRef]

6. Bueno, C.S.P.; Oliveira, D.P.; Pelegrine, R.A.; Fontana, C.E.; Rocha, D.G.P.; Gutmann, J.L.; Bueno, C.E.S. Fracture incidence of WaveOne Gold files: A prospective clinical study. Int. Endod. J. 2020, 53, 1192-1198. [CrossRef]

7. Cheung, G.S.P. Instrument fracture: Mechanisms, removal of fragments, and clinical outcomes. Endod. Top. 2009, 16, 1-26. [CrossRef]

8. McGuigan, M.B.; Louca, C.; Duncan, H.F. The impact of fractured endodontic instruments on treatment outcome. Br. Dent. J. 2013, 214, 285-289. [CrossRef]

9. Zhou, H.; Peng, B.; Zheng, Y.-F. An overview of the mechanical properties of nickeltitanium endodontic instruments. Endod. Top. 2013, 29, 42-54. [CrossRef]

10. Shen, Y.; Zhou, H.; Zheng, Y.; Peng, B.; Haapasalo, M. Current challenges and concepts of the thermomechanical treatment of nickel-titanium instruments. J. Endod. 2013, 39, 163-172. [CrossRef]

11. Testarelli, L.; Plotino, G.; Al-Sudani, D.; Vincenzi, V.; Giansiracusa, A.; Grande, N.M.; Gambarini, G. Bending properties of a new nickel-titanium alloy with a lower percent by weight of nickel. J. Endod. 2011, 37, 1293-1295. [CrossRef] [PubMed]

12. Zupanc, J.; Vahdat-Pajouh, N.; Schäfer, E. New thermomechanically treated NiTi alloys-A review. Int. Endod. J. 2018, 51, 1088-1103. [CrossRef] [PubMed]

13. Zhou, H.; Shen, Y.; Zheng, W.; Li, L.; Zheng, Y.; Haapasalo, M. Mechanical properties of controlled memory and superelastic nickel-titanium wires used in the manufacture of rotary endodontic instruments. J. Endod. 2012, 38, 1535-1540. [CrossRef] [PubMed]

14. Gutmann, J.L.; Gao, Y. Alteration in the inherent metallic and surface properties of nickel-titanium root canal instruments to enhance performance, durability and safety: A focused review. Int. Endod. J. 2012, 45, 113-128. [CrossRef]

15. Pérez-Higueras, J.J.; Arias, A.; de la Macorra, J.C.; Peters, O.A. Differences in cyclic fatigue resistance between ProTaper Next and ProTaper Universal instruments at different levels. J. Endod. 2014, 40, 1477-1481. [CrossRef]

16. Uygun, A.D.; Kol, E.; Topcu, M.K.C.; Seckin, F.; Ersoy, I.; Tanriver, M. Variations in cyclic fatigue resistance among ProTaper Gold, ProTaper Next and ProTaper Universal instruments at different levels. Int. Endod. J. 2016, 49, 494-499. [CrossRef]

17. González-Chapela, J.; Castelo-Baz, P.; Varela-Patiño, P.; Martín-Biedma, B.; Ruíz-Piñón, M. Alternating versus continuous rotation: Root canal transportation and centering ratio with the ProTaper Next. J. Conserv. Dent. 2017, 20, 255-259. [CrossRef]

18. Elnaghy, A.M. Cyclic fatigue resistance of ProTaper Next nickel-titanium rotary files. Int. Endod. J. 2014, 47, 1034-1039. [CrossRef]

19. Hieawy, A.; Haapasalo, M.; Zhou, H.; Wang, Z.; Shen, Y. Phase transformation behavior and resistance to bending and cyclic fatigue of ProTaper Gold and ProTaper Universal instruments. J. Endod. 2015, 41, 1134-1138. [CrossRef]

20. Elnaghy, A.M.; Elsaka, S.E. Mechanical properties of ProTaper Gold nickel-titanium rotary instruments. Int. Endod. J. 2016, 49, 1073-1078. [CrossRef]

21. Algahtani, F.; Huang, X.; Haapasalo, M.; Wang, Z.; Hieawy, A.; Zhang, D.; Aleksejuniene, J.; Shen, Y. Fatigue resistance of ProTaper gold exposed to high-concentration sodium hypochlorite in double curvature artificial canal. Bioact. Mater. 2019, 4, 245-248. [CrossRef] [PubMed]

22. Keskin, C.; Inan, U.; Guler, D.H.; Kalyoncuoğlu, E. Cyclic fatigue resistance of XP-Endo Shaper, K3XF, and ProTaper Gold nickel-titanium instruments. J. Endod. 2018, 44, 1164-1167. [CrossRef] [PubMed]

23. Özyürek, T.; Yılmaz, K.; Uslu, G. The effects of autoclave sterilization on the cyclic fatigue resistance of ProTaper Universal, ProTaper Next, and ProTaper Gold nickeltitanium instruments. Restor. Dent. Endod. 2017, 42, 301-308. [CrossRef] [PubMed]

24. Ruiz-Sánchez, C.; Faus-Matoses, V.; Alegre-Domingo, T.; Faus-Matoses, I.; Faus-Llácer, V.-J. An in vitro cyclic fatigue resistance comparison of conventional and new generation nickel-titanium rotary files. J. Clin. Exp. Dent. 2018, 10, e805-e809. [CrossRef] [PubMed] 
25. Castelló-Escrivá, R.; Alegre-Domingo, T.; Faus-Matoses, V.; Román-Richon, S.; FausLlácer, V.J. In vitro comparison of cyclic fatigue resistance of ProTaper, WaveOne, and Twisted Files. J. Endod. 2012, 38, 1521-1524. [CrossRef] [PubMed]

26. Montenegro-Santillan, R.; Alegre-Domingo, T.; Faus-Matoses, V.; Faus-Llacer, V. An in vitro comparison of cyclic fatigue resistance of ProTaper Universal and GT series X files. Med. Oral Patol. Oral Cir. Bucal 2013, 18, e533-e536. [CrossRef]

27. Plotino, G.; Grande, N.M.; Cordaro, M.; Testarelli, L.; Gambarini, G. A review of cyclic fatigue testing of nickel-titanium rotary instruments. J. Endod. 2009, 35, 1469-1476. [CrossRef]

28. Zubizarreta-Macho, Á.; Mena Álvarez, J.; Albaladejo Martínez, A.; Segura-Egea, J.J.; Caviedes Brucheli, J.; Agustín-Panadero, R.; López Píriz, R.; Alonso-Ezpeleta, Ó. Influence of the Pecking Motion Frequency on the Cyclic Fatigue Resistance of Endodontic Rotary Files. J. Clin. Med. 2019, 9, 45. [CrossRef]

29. Zubizarreta-Macho, A.; Alonso-Ezpeleta, O.; Albaladejo Martínez, A.; Faus Matoses, V.; Caviedes Brucheli, A.; Agustín-Panadero, R.; Mena Álvarez, J.; Vizmanos Martínez-Berganza, F. Novel Electronic Device to Quantify the Cyclic Fatigue Resistance of Endodontic Reciprocating Files after Using and Sterilization. Appl. Sci. 2020, 10, 4962. [CrossRef]

30. Pruett, J.P.; Clement, D.J.; Carnes, D.L., Jr. Cyclic fatigue testing of nickel-titanium endodontic instruments. J. Endod. 1997, 23, 77-85. [CrossRef]

31. Wei, X.; Ling, J.; Jiang, J.; Huang, X.; Liu, L. Modes of failure of ProTaper nickel-titanium rotary instruments after clinical use. J. Endod. 2007, 33, 276-279. [CrossRef] [PubMed]

32. Gambarini, G. Cyclic fatigue of nickel-titanium rotary instruments after clinical use with low-and high-torque endodontic motors. J. Endod. 2001, 27, 772-774. [CrossRef] [PubMed]

33. Parashos, P.; Gordon, I.; Messer, H.H. Factors influencing defects of rotary nickel-titanium endodontic instruments after clinical use. J. Endod. 2004, 30, 722-725. [CrossRef] [PubMed]

34. Spili, P.; Parashos, P.; Messer, H.H. The impact of instrument fracture on outcome of endodontic treatment. J. Endod. 2005, 31, 845-850. [CrossRef] [PubMed]

35. Strindberg, L. The dependence of the results of pulp therapy on certain factors. Acta Odontol. Scand. 1956, 14, $1-175$.

36. ANSI/ADA Specification N $N^{\circ}$ 28-2002. Root Canal Files and Reamers, Type K for Hand Use; American Dental Association: Chicago, IL, USA, 2002.

37. ISO 3630-3631:2008. Dentistry—Root Canal Instruments—Part 1: General Requirements and Test Methods; ISO: Geneva, Switzerland, 2008.

38. Lopes, H.P.; Britto, I.M.; Elias, C.N.; de Machado Oliveira, J.C.; Neves, M.A.; Moreira, E.J.; Siqueira, J., Jr. Cyclic fatigue resistance of ProTaper Universal instruments when subjected to static and dynamic tests. Oral Surg. Oral Med. Oral Pathol. Oral Radiol. Endod. 2010, 110, 401-404. [CrossRef] [PubMed]

39. Zelada, G.; Varela, P.; Martin, B.; Bahillo, J.; Magan, F.; Ahn, S. The Effect of rotational speed and the curvature of root canals on the breakage of rotary endodontic instruments. J. Endod. 2002, 28, 540-542. [CrossRef]

40. Kitchens, G.G.; Liewehr, F.R.; Moon, P.C. The effect of operational speed on the fracture of nickel-titanium rotary instruments. J. Endod. 2007, 33, 52-54. [CrossRef]

41. Gao, Y.; Shotton, V.; Wilkinson, K.; Phillips, G.; ben Johnson, W. Effects of raw material and rotational speed on the cyclic fatigue of ProFile Vortex rotary instruments. J. Endod. 2010, 36, 1205-1209. [CrossRef]

42. Santoro, M.; Nicolay, O.F.; Cangialosi, T.J. Pseudoelasticity and thermoelasticity of nickel-titanium alloys: A clinically oriented review. Part I: Temperature transitional ranges. Am. J. Orthod. Dentofac. Orthop. 2001, 119, 587-593. [CrossRef]

43. Gundogar, M.; Ozyurek, T. Cyclic fatigue resistance of OneShape, HyFlex EDM, WaveOne Gold, and Reciproc Blue nickel-titanium instruments. J. Endod. 2017, 43, 1192-1196. [CrossRef] [PubMed]

44. Keskin, C.; Inan, U.; Demiral, M.; Keles, A. Cyclic fatigue resistance of Reciproc Blue, Reciproc, and WaveOne Gold reciprocating instruments. J. Endod. 2017. [CrossRef] [PubMed]

45. Arias, A.; Perez-Higueras, J.J.; de la Macorra, J.C. Differences in cyclic fatigue resistance at apical and coronal levels of Reciproc and WaveOne new files. J. Endod. 2012, 38, 1244-1248. [CrossRef] [PubMed]

46. Elnaghy, A.M.; Elsaka, S.E. Laboratory comparison of the mechanical properties of TRUShape with several nickel-titanium rotary instruments. Int. Endod. J. 2017, 50, 805-812. [CrossRef] [PubMed]

47. Zafar, M.S. Impact of Endodontic Instrumentation on Surface Roughness of Various Nickel-Titanium Rotary Files. Eur. J. Dent. 2020. [CrossRef] 
48. Seracchiani, M.; Miccoli, G.; Di Nardo, D.; Zanza, A.; Cantore, M.; Gambarini, G.; Testarelli, L. Effect of flexural stress on torsional resistance of NiTi instruments. J. Endod. 2020. [CrossRef]

Publisher's Note: MDPI stays neutral with regard to jurisdictional claims in published maps and institutional affiliations.

(C) 2020 by the authors. Licensee MDPI, Basel, Switzerland. This article is an open access article distributed under the terms and conditions of the Creative Commons Attribution (CC BY) license (http://creativecommons.org/licenses/by/4.0/). 